\title{
Todos y ninguno. Crónica urbana y reciclaje en la obra de Antonio Muñoz Molina
}

\section{Everyone and no one. Urban Chronicle and Recycling in Antonio Muñoz Molina's Work}

\author{
Teresa Georgina González Arce \\ Universidad de Guadalajara, México \\ liboria_maple@yahoo.com.mx
}

Resumen: Antonio Muñoz Molina inició su carrera literaria como periodista cultural del Diario de Granada, medio en el cual aparecieron, entre 1982 y 1983, las crónicas urbanas que un año más tarde conformarían su primer libro: El Robinson urbano (1984). En el prólogo de la reedición que Seix Barral hizo en 1993, Pere Gimferrer advertía el esmero estilístico de la prosa de Muñoz Molina y apuntaba que la Granada urbana del autor de Beatus ille y El invierno en Lisboa podía ser todas las ciudades y ninguna. En 2018, Muñoz Molina publica Un andar solitario entre la gente, un texto desbordado, ruidoso y disgregado, como las mismas ciudades que evoca. Ambas obras son los cabos de una trayectoria marcada por el flâneur, esa figura que nace con Poe, adquiere forma en Baudelaire, es interpretada por Benjamin y conforma una tradición literaria de caminantes que pasean por la ciudad moderna con una mirada al mismo tiempo fascinada, receptiva y crítica. Tanto $U n$ andar solitario entre la gente como El Robinson urbano tienen en común 
la integración de elementos ficcionales en un género referencial como la crónica periodística. En este artículo trataré de destacar los nexos que unen estas dos obras e intentaré relacionarlas con lo que considero más relevante en la propuesta que presenta Muñoz Molina en este peculiar relato urbano del siglo xxI.

Palabras clave: Crónica, ciudad, Espańa, narrativa, periodismo.

Abstract: Antonio Muñoz Molina began his literacy career as a cultural journalist at the Diario de Granada, in which he published his urban chronicles between 1982 and 1983. A year after that series of chronicles became his first book: El Robinson urbano (1984). In the prologue of the Seix Barral 1993 reissue, Pere Gimferrer warned about the stylistic care of Muñoz Molina's prose and suggested that the author's urban Granada from the Beatus ille and Winter in Lisbon could be any city or none. Both works are the ends of a trajectory marked by the flaneur, the figure that took form with Baudelaire, was interpreted by Benjamin and became part of a literary tradition of walkers across the modern city with an amazed, receptive and critical look. Both, Un andar solitario entre la gente and El Robinson urbano, have a common integration of fictional elements in a referential genre like the journalistic chronicle. In this article I will try to highlight the links between these two literary works and relate them to which I consider the most relevant in this proposal that Muñoz Molina presents at this peculiar urban story form the XXI century.

Keywords: Chronicle, City, Spain, Literacy, Journalism.

Recibido: 9 de octubre de 2019

Aceptado: 2 de febrero de 2020 https://dx.doi.org/10.15174/rv.vi26.506 
Conocido principalmente como novelista, Antonio Muñoz Molina inició su carrera literaria como periodista cultural del Diario de Granada, medio en el cual aparecieron, entre 1982 y 1983, las crónicas urbanas que un año más tarde habrían de conformar lo que sería su primer libro: El Robinson urbano (1984). En el prólogo de la reedición que Seix Barral hizo en 1993, Pere Gimferrer advertía el esmero estilístico de la prosa de Muñoz Molina y apuntaba que la Granada urbana del autor de Beatus ille y El invierno en Lisboa podía ser todas las ciudades y ninguna, rasgo que la hermanaba con el Madrid de Gómez de la Serna o con el Nueva York avistado por García Lorca en Poeta en Nueva York. Como podremos ver enseguida, este atributo conviene también a todas las ciudades que Muñoz Molina ha habitado desde entonces (Muñoz Molina, 1995). ${ }^{1}$

Es necesario evocar esta obra prima a propósito de $U n$ andar solitario entre la gente (2018) si consideramos que los rasgos estilísticos, temas y apegos que los lectores descubrieron hace treinta y cuatro años en aquellas crónicas granadinas siguen teniendo vigencia en trabajos más recientes del autor, en la medida en que continúan orientando y dando sentido a una exploración estética que, desde entonces, se ha propagado en obras como Sefarad o Ventanas de Manhattan, así como en las columnas que Muñoz Mo-

${ }^{1}$ En la opinión de Jordi Gracia y Domingo Ródenas de Moya, tanto El Robinson urbano como Diario del Nautilus "vinieron a contribuir de una manera rotunda a la frescura y densidad de un género que ha de crecer en nuestras letras desde esos años con una notable riqueza de matices y tonalidades". Desde una perspectiva que comprende el desarrollo del ensayo y del artículo en España, país con una gran tradición de articulistas notables que va de Mariano José de Larra y Leopoldo Alas "Clarín” a Benito Pérez Galdós, José Ortega y Gasset y Francisco Umbral (por solo citar unos cuantos nombres), Gracia y Ródenas de Moya consideran que Antonio Muñoz Molina ha pergeñado, en su labor periódica, "algunos de los momentos más tensos y hermosos de un excepcional estilo literario y una rara densidad emocional” (Gracia y Ródenas, 2015: 476-477). 
lina ha publicado en la prensa periódica de manera prácticamente ininterrumpida desde el inicio de su carrera.

La afinidad que existe entre las obras que acabo de citar permitiría agruparlas en un subconjunto cuyo elemento común fuese la percepción de la ciudad como un cronotopo que adquiere sentido gracias el sujeto que la recorre y la mira. En el presente artículo, me enfocaré principalmente en El Robinson urbano y Un andar solitario entre la gente debido a que ambas obras son los cabos de una trayectoria marcada por el flâneur, esa figura que nace con Poe, adquiere forma en Baudelaire, es interpretada por Benjamin y conforma una tradición literaria de caminantes que pasean por la ciudad moderna con una mirada al mismo tiempo embelesada, receptiva y crítica. Ambas obras tienen en común la integración de elementos ficcionales en un género referencial como la crónica periodística.

Pese a los elementos comunes que estas dos obras presentan, existen marcadas diferencias entre ellas. Si bien en los dos libros encontramos esa mirada inteligente y sensible del cronista, la complejidad de la experiencia citadina, evidente en ambas obras, es congruente con la transformación que las ciudades han padecido en los últimos treinta ańos. Mientras que los textos que integran El Robinson urbano se suceden en una armonía que debe mucho a la brevedad y contención de cada artículo, y a la fascinación que el escritor tiene por Granada - una ciudad heredera de la cultura árabe, abundante en referencias literarias, históricas y personales-, Un andar solitario entre la gente, en cambio, es un texto desbordado, ruidoso y disgregado como las mismas ciudades que evoca-Nueva York y Madrid, principalmente. ${ }^{2}$

${ }^{2}$ Dos de los epígrafes iniciales de la obra revelan que esta crónica de Muñoz Molina debe su título a dos versos similares de dos sonetos que definen el amor: uno de Luís de Camôes, "Amor é fogo que arde sem se ver...", y otro de Francisco de Quevedo, "Es hielo abrasador, es fuego helado...". 
En las siguientes líneas expondré que, con todo y sus diferencias, ambas obras presentan una continuidad estética que consiste en incorporar las experiencias urbanas del pasado -las propias, las de la escritura, y las de los paseantes literarios que las inspiran- en el presente. Sobre todo, me interesa mostrar cómo, a pesar de lo que su título sugiere, el caminar que protagoniza esta compleja y peculiar crónica urbana del siglo XXI nunca es solitario, pues lo acompańa y lo orienta toda una tradición que se remonta, por lo menos, a la invención de la ciudad moderna.

\section{Primer retrato del flâneur: El Robinson urbano}

En el espacio literario de Antonio Muñoz Molina, el punto de salida del flâneur se encuentra, sin duda, en El Robinson urbano. Las treinta y dos crónicas que conforman el libro tienen una extensión breve y homogénea, marcada por las exigencias del diario donde se publicaban. En ellas el cronista habla de sus paseos por Granada, ciudad en la que habitan también Robinson -quien deambula por las calles con el mismo asombro de Robinson Crusoe al descubrir la isla desierta a la que llegó tras el naufragio- y un historiador sefardí llamado Apolodoro como el célebre cronista de la Antigüedad griega. Quien dice escribir esta columna semanal no solo está acompañado de estos dos personajes sino de toda una galería de escritores a quienes se rinde tributo en "Escuela de robinsones", texto con el cual inicia el libro y que da testimonio de la deuda que Muñoz Molina tiene con esa estirpe de paseantes urbanos en la que se encuentran autores como De Quincey, Poe, Baudelaire, Joyce, Benjamin y García Lorca.

En este libro, Granada aparece como una ciudad compuesta por los recorridos diacrónicos que los paseantes han marcado en sus calles. Lugar de descubrimiento y divagación, Granada es un espacio de planos superpuestos que se revelan a los ojos siempre 
atentos del cronista-flâneur. Encontramos una descripción muy esclarecedora de esta composición urbana en "El juego de las conmemoraciones", uno de los textos compilados en El Robinson urbano:

Sobre el plano visible de la ciudad se impone una segunda ciudad imaginaria, un tapiz en cuyo delicado dibujo se enlazan los pormenores de la fascinación y la memoria, así resulta que cruzar una plaza se convierte en un viaje por el tiempo, y el solo gesto de subir una escalera o entreabrir una puerta del Albayzín puede conducirnos, a través de espejos inadvertidos, a una estancia imaginada por Washington Irving cuyas ventanas, al abrirlas, ofrecen un paisaje de Ania Nicolas (Muñoz Molina, 1993: 26).

La idea de una ciudad donde se superpongan la realidad, la memoria y el deseo, y en la cual coexistan los personajes reales o imaginarios que han caminado por ella, constituye uno de los tópicos de las crónicas escritas por Muñoz Molina desde los años ochenta y reaparece nuevamente, como se verá después, en $U n$ andar solitario. En "El juego de las conmemoraciones", una de las crónicas de El Robinson urbano, la composición cronotópica de la ciudad es comparada por el autor con un misterioso "Juego de la oca" donde "el azar de nuestros pasos", leemos, "puede conducirnos al porvenir en un salto prodigioso, sumirnos durante un lunes entero en el pozo de la desdicha o devolvernos del laberinto al treinta para empezar de nuevo esa ardua peregrinación que muy probablemente no termine nunca” (Muñoz Molina, 1993: 26).

Es tal vez esta composición la que hizo necesario que el cronista no anduviera solo, sino que encontrara a los dos personajes ficticios que, por cierto, subrayan la conjunción entre la literatura, la historia, y la experiencia personal representada por el propio cronista. Importa prestar atención a Apolodoro, un personaje que re- 
aparecerá años más tarde en Un andar solitario entre la gente, y que en este primer libro se describe como un hombre "singularmente tenue, con gafas redondas y perilla", que escoge, para hablar, los ángulos sombríos, solo mira sus propias manos mientras habla y vive en una casa situada en el Albayzín, uno de los barrios altos y antiguos de la Granada musulmana, y desde la cual puede verse la Alhambra (Muñoz Molina, 1993: 67-68).

Autor de una Enciclopedia de la desolación en veintisiete volúmenes y un apéndice, Apolodoro es un viajero en el tiempo, autor de "sosegadas utopías" e inventor de "máquinas estrafalarias". Este cabalista sefardí, cuyo mayor deseo es ser Nadie, llegó a Granada con una llave grande que, según dice, fue atesorada por sus antepasados granadinos para que un día pudiera recuperar la casa de la que fueron expulsados en la Edad Media (Muñoz Molina, 1993: 90-91).

\section{Apolodoro en el siglo XXI}

En las novelas ambientadas en Mágina, la ciudad imaginaria de Muñoz Molina, hay personajes e historias que reaparecen en obras diferentes, creando la ilusión de conformar un universo autónomo. En Un andar solitario entre la gente, el personaje de Apolodoro, el sefardí errante de El Robinson urbano resurge treinta años después en el Café Comercial de Madrid como uno más de los caminantes que el cronista de Un andar solitario encuentra en su camino. El cronista describe ese mítico café, al que solían acudir madrileños tan ilustres como Benito Pérez Galdós, Antonio Machado, Ignacio Aldecoa o Rafael Sánchez Ferlosio, como un espacio de "atmósfera acuática”, de claridades entreveradas con penumbras, propicio para encuentros extraordinarios: 
Yo venía en el Metro. Emergía a la luz de la glorieta de Bilbao. Compraba uno o dos periódicos en el kiosco y alguna película rara y casi siempre inesperada y disfrutaba a conciencia de ingresar en la gran concavidad del café, como en otro Madrid simultáneo y en otra región del tiempo; no un depósito o un remanso de pasado, sino un presente que no hubiera cortado en seco sus lazos con él (Muñoz Molina, 2018a:105).

Una atmósfera de relato de ficción semejante a la que tenían algunos fragmentos de El Robinson urbano se instala en esta nueva crónica desde que el cronista emerge del Metro como quien sale de un túnel del tiempo. El guiño servirá de introducción a todo un segmento del libro en el que este hombre, que unos días antes había llamado la atención del protagonista, se sienta junto a él y le hace notar que, aunque no lo recuerde, él solía visitarlo en la casa que tenía en el Albaicín. "Usted no se acuerda”, le explica ese hombre en quien reconocemos a Apolodoro, "no porque haya pasado tanto tiempo sino porque ha tenido varias vidas completas después” (Muñoz Molina, 2018a: 106). La aparición de este viajero en el tiempo en pleno siglo XXI transmite una seńal de continuidad entre el pasado y el presente que reconocerán fácilmente quienes hayan leído El Robinson urbano. Estos últimos podrán constatar, igualmente, que el sujeto que deambulaba por las calles de Granada en los años ochenta no es otro que el protagonista de Un andar solitario entre la gente.

Tras la presentación, Apolodoro explica a nuestro viejo amigo algunas de sus teorías, como la del carácter metafórico de la expresión "Borrón y cuenta nueva”, que postula la interconexión de la memoria y la imaginación. "Los recuerdos suelen sobrevivir pero no se sabe que lo son", explica Apolodoro, sin pronunciar nunca su nombre. "Aparecen con mucha claridad precisamente en los sueños que se borran sin rastro cuando usted despierta [...]. 
Usted inventa algo y no sabe que está recordando. Usted cree estar fantaseando un hecho futuro y lo que imagina es un recuerdo perdido" (Muñoz Molina, 2018a:107). Es, sin embargo, otro de sus hallazgos una ciencia que él llama "deambulología", lo que permite vislumbrar la necesidad que este personaje tiene de ser Nadie, tal como él mismo dijo una vez al cronista de El Robinson urbano.

Sé tú mismo si no puedes ser Batman. ${ }^{3}$ [...] Como su nombre indica, la Deambulología es el estudio de los itinerarios seguidos por escritores, artistas, científicos, visionarios, indigentes y lunáticos: bien los habituales y mantenidos a lo largo de una vida entera -los paseos de Kant son el ejemplo clásico-, bien los irregulares, los repentinos, los que nunca han tenido regreso. Hay dudas sobre si la Deambulología es un saber autosuficiente, o si en realidad vendría a ser una rama de la Topobiografía, cuya adivinable finalidad es el estudio de los domicilios distintos en los que han vivido o viven estos mismos personajes, procurando establecer, con ayuda de mapas detallados, los posibles patrones psicoespaciales o sociovitales (la invención desde la nada de todo un lenguaje especializado es otro de los desafíos inabarcables para una sola persona) (Muñoz, 2018a: 119).

Entre las aportaciones que la deambulología desarrollada por Apolodoro entrega a la arquitectura textual de Un andar solitario entre la gente, está la posibilidad de incorporar un procedimiento al que Muñoz Molina ya había recurrido en obras anteriores tales como Sefarad. Conviene recordar que una parte importante de esa "novela de novelas" que es Sefarad está conformada por paráfrasis

3 "Siempre se tú mismo, a menos que puedas ser Batman y hacer que toda tu ciudad se entere” es la frase con la que la compañía Circus promocionó en 2017 la película Lego Batman de Warner Bros. Pictures. 
y comentarios de las semblanzas y biografías que el personaje que narra y organiza la obra conoce, ya sea por lecturas o por relatos transmitidos de forma oral. Enfocado en las experiencias del desarraigo y la exclusión, sobre todo cuando éstas son provocadas por totalitarismos que, pese a la supuesta oposición ideológica entre ellos, acaban equiparándose en la crueldad y la negación del otro. Importa recordar también que el hilo que permite vincular estas historias -la enfermedad padecida por el protagonista- crea un nexo de empatía entre el narrador y las víctimas de todos los tipos de exclusión y alienación. ${ }^{4}$

De forma análoga, Un andar solitario entre la gente echa mano de relatos biográficos que cuentan las condiciones casi siempre adversas en las cuales los paseantes de esa tradición del flâneur recorrían las calles de Londres, Nueva York, París, Madrid o Lisboa: Oscar Wilde recorriendo los bulevares donde están los hoteles baratos de París, y en los cuales firma con el seudónimo de Sebastian Melmoth para pasar inadvertido. Baudelaire, insomne y nervioso porque no ha conseguido ganar más que un obrero o un artesano pese a haber publicado y traducido incansablemente durante veinte ańos. Melville, De Quincey, Apollinaire, Benjamin, Pessoa,

${ }^{4}$ En Sefarad, la instancia narrativa se apropia de la experiencia de exclusión vivida por los personajes históricos, víctimas del rechazo, vinculándola a su propia enfermedad: "Eres el médico que aguarda en la penumbra de su despacho al paciente a quien debe darle la noticia de su enfermedad y teme el momento de su llegada y el de las neutras palabras necesarias, pero sobre todo eres el otro, el enfermo, que todavía no sabe que lo es, que aún viene tranquilamente por una calle habitual dándose tiempo porque llega temprano a la cita, hojeando un periódico que acaba de comprar y que se quedará olvidado en la mesita de la sala de espera, un periódico con una fecha igual a cualquier otra en la sucesión de los días y que sin embargo marcará la frontera, el antes y el después, el último día de una vida y el comienzo de otra en la que ya no puedes ser el mismo, en la que recordarás a quien fuiste hasta ese momento como alguien más ajeno a ti que un desconocido" (Muñoz Molina, 2001: 458). 
Proust. El propio Muñoz Molina en otras épocas de su vida. Algunos de ellos podrían haberse cruzado en vida o transitado las mismas calles en épocas distintas. Todos podrían haber dejado sus huellas invisibles por las calles de Madrid, París o Lisboa que él mismo camina mientras graba anuncios publicitarios y mira todo con ojos atentos. Él, que es todos y ninguno, y que en algunos párrafos deja de tener identidad propia para dar voz a todos los caminantes urbanos. “¡Yo soy Nadie! ¿Quién eres tú? / ¿Eres Nadie también tú?”, dice Emily Dickinson en los versos que figuran en la segunda parte del libro, que se titula "Don Nadie" y comienza de la siguiente manera:

Yo que tantos Hombres He Sido. Abre los ojos en la oscuridad y como solo oye el silencio no tiene ninguna pista sobre la ciudad donde se encuentra, sobre la hora y el día y al año y la época en que ha despertado. No tiene nombre ahora mismo, ni biografía, ni cara. En su conciencia no hay una separación precisa entre la vigilia y el sueño, igual que no la hay entre la sombra de su cuerpo y los bultos de negrura inmóvil de la habitación, y la oscuridad misma del aire. [...] Podría haber despertado de un sueńo de opio o de alcohol en un cuartucho atestado de libros y papeles y periódicos polvorientos en Edimburgo, en el suelo de una taberna de Baltimore [...]. Puede estar abriendo los ojos en un cuarto de pensión con las paredes encaladas y no saber si ha despertado en Ibiza o en Portbou (Muñoz Molina, 2018a: 353). ${ }^{5}$

${ }^{5}$ Encontramos, también en Sefarad, esta obsesión por la disolución de la identidad. Un ejemplo claro de esto es uno de los capítulos del libro -titulado "Eres"-, en cuyas líneas iniciales se lee: "No eres una sola persona y no tienes una sola historia, y ni tu cara ni tu oficio ni las demás circunstancias de tu vida pasada o presente permanecen invariables" (Muñoz Molina, 2001: 443). 


\section{Paseantes urbanos del siglo XXI}

Más que como un homenaje a la figura del flâneur, Un andar solitario entre la gente podría leerse como una respuesta a un problema que seguramente se planteó Muñoz Molina al comenzar a escribir su libro: ¿cómo debe escribirse una crónica urbana en el siglo Xxı? Si las ciudades se han transformado y desbordado a un ritmo que hubiera resultado inverosímil a los paseantes de las ciudades del siglo XIX, ¿qué sentido tendría insistir en narrar la experiencia urbana como si la noción misma de ciudad hubiera seguido inalterable desde su nacimiento como entidad moderna?

Una de las convicciones más firmes que recorren la obra de este escritor es quizás que el pasado puede ser un espejo revelador para el presente, y tal vez el único medio que los seres humanos tenemos para enfrentar los retos que vamos encontrando en el camino. En el ámbito literario -y, en particular, en Un andar solitario entre la gente-, la confianza que tiene el autor en la resonancia del pasado es perceptible en muchos aspectos, desde el título y los epígrafes, hasta la forma de la obra, pasando por el entramado intertextual que recorre sus páginas. La obra en sí misma constituye un diálogo continuo con la tradición literaria, y es en este diálogo donde, al parecer, el autor ha encontrado respuestas para escribir esta nueva crónica.

Si bien es verdad que el flâneur que encontramos en este libro se acoge al arquetipo que ya había utilizado en ocasiones anteriores, también es cierto que esta vez son más abundantes y perceptibles las reflexiones del cronista acerca de la realidad que sus ojos enfrentan en varias ciudades que bien podrían parecer la misma. La ciudad es ruidosa, caótica, excluyente, y quien camina por ella es constantemente interpelado y solicitado por las voces de un sinfín de publicidades. El caminante anda solo por la ciudad para registrar a detalle lo que hay en ella, pero rara vez encuentra ahí la 
coherencia simbólica y discursiva que caracterizaban las crónicas de sus recorridos anteriores: todo es ruido y basura, gente anónima y solicitudes urgentes de adquirir algún producto que bien puede ser un teléfono, la felicidad o una noche de placer con prostitutas traídas de América o Europa del Este.

Nuestro paseante sale a la calle cada mañana con todos los atributos que la tradición le ha asignado y con un equipo formado por su calzado deportivo, agua, un bocadillo, vino y un portafolios donde guarda libretas, tijeras y pegamento: especie de oficina que le permite instalarse en cualquier lugar para escribir y pegar frases y fotos de periódicos y reclamos publicitarios que recoge según avanza. En la grabadora de su teléfono, además, graba íntegro lo que lee y registra las conversaciones de la gente que camina en torno suyo. A veces, cuando llega el momento de transcribir la basura sonora que ha registrado en su camino, nota que también han quedado grabados sus propios pasos e incluso el sonido de las monedas que lleva guardadas en el bolsillo, junto a su teléfono.

En el plano material, este "experimento vital" -como este recorrido es llamado al final del texto- se traduce en una edición que reproduce algunos de los montajes que el autor hizo en sus cuadernos, así como fotografías de los autores evocados. La frase inicial de cada párrafo, destacada con tipografía Bold o negrita, es una frase publicitaria o letrero visto en la calle, y algunos de estos párrafos están en itálicas para indicar que se trata de notas extraídas de la prensa. En algunas partes del libro, el texto no está justificado, lo cual sirve para insistir en que el libro es la reproducción de un cuaderno. El conjunto parece, además, apegarse al consejo que da James Joyce en el fragmento situado como epígrafe de la obra: "Un libro no se debe proyectar de antemano: a medida que uno escribe irá tomando forma, sometido a los impulsos emocionales de uno" (Muñoz Molina, 2018a: 5). 
Algunas de las notas críticas que se publicaron al salir esta obra que, por cierto, es descrita en la cuarta de forros como una "audaz novela”, apuntaban que se trataba de un texto innecesariamente largo, que carecía de argumento e, incluso, "pese al interés objetivo del proyecto, me temo que es difícil que este método atrape el interés de muchos lectores, de por sí avasallados por el mismo torbellino semiótico que se describe. Éste es un libro valioso por sintomático, con páginas espléndidas, que, sin embargo, no me parece que defina un camino futuro transitable" (Ródenas de Moya Domingo, 2018).

Hubo quienes, con razón, se extrañaron de que la editorial hubiese llamado "novela" a algo que, a todas luces, se parecía más a un cuaderno, un dietario o una crónica, término que me parece más adecuado tomando en cuenta lo que he expuesto líneas arriba. Por mi parte, independientemente de lo que el lector consiga vislumbrar en estas páginas, me parece que vale la pena buscar en el texto, y también en las entrevistas concedidas por el autor, una descripción que se adapte a lo que él tenía en mente al emprender su trabajo pues, tal como afirma el crítico Fernando Valls en su artículo, no toda la prosa debe ser considerada parte del género novelístico:

En la contracubierta se le llama "audaz novela", si bien en las entrevistas que ha concedido, el autor se resiste a tener que definirlo, o confiesa que no le molesta que sea tachado de tal, aunque luego se refiera a él como diario o novela indistintamente, e incluso en el texto prefiera el término collage al de libro (p. 348). [...] No creo, por tanto, que estemos ante una novela. Incluso formalmente, en su aspecto físico, por las manchas que genera la tinta sobre el papel produce la impresión de un singular diario, en el que no faltan los poemas (Valls, 2018). 


\section{Collage, discordancia y residuos: elementos de la nueva crónica}

Tal como hace notar Fernando Valls, Muñoz Molina ha descrito Un andar solitario entre la gente como una especie de collage compuesto a partir de desechos. Lejos de ser una novedad, el reciclaje de la basura con fines expresivos es un procedimiento que ha existido desde siempre ya que las sociedades siempre han utilizado aquello que tenían más a mano. Llegados a este punto, conviene recordar que, según explicó hace años el crítico Saúl Yurkiévich,

El collage recorta fragmentos preformados, extraídos de obras o mensajes prexistentes y los yuxtapone para integrarlos en un conjunto disímil, de contextualidad compuesta y antagónica. Disjecta membra, el collage presupone una poética basada en la discontinuidad y la disonancia, en las superposiciones aleatorias, en las contigüidades insólitas, en lo multiforme y multireferente. Acumulación caótica, adicta a la estética de la profusión, ejerce la potencia implicativa; crea una dinámica anexionista, dinámica adhesiva, capaz de involucrar la agitada disparidad de lo real" (1986: 53).

Es interesante recordar que Walter Benjamin, uno de los escritores cuya obra sirve de modelo a Un andar solitario entre la gente, entendía que lo propio de la mirada del flâneur era rastrear, en la ciudad y en la multitud, fragmentos residuales y dispersos que luego reconstruye en forma de identidades especulativas. Este reciclaje es comparado por el propio Benjamin con el montaje, procedimiento artístico que busca conservar el fragmento de manera que no se supedite a una lógica de ordenación jerárquica, a una obra de arte orgánica o un relato lineal (Araya Alarcón: 32). Para Nicolás López, este procedimiento "es la respuesta constructi- 
va de Benjamin ante la experiencia de la disolución y, sobre todo, de la dispersión de las cosas mismas en el caos de la gran ciudad". El montaje, continúa López, supone "un gran trabajo positivo sobre las ruinas, los harapos, los desperdicios de la historia”, lo cual permite a Benjamin "componer los materiales de una manera que no se supediten a una lógica de ordenación jerárquica o a un relato lineal” (López Nicolás, 2013: 1-13).

En el caso del libro que nos ocupa podríamos decir que el autor español evoca la apuesta de Benjamin realizando una especie de montaje con fragmentos publicitarios, lo cual es para él el equivalente verbal de la basura. En una entrevista, el escritor afirma que en su libro quiso establecer "un nexo entre desecho material y el desecho verbal de la publicidad, que continuamente está alentando a comprar cosas destinadas a convertirse en desecho". En este sentido, continúa el autor, "el libro tiene un componente político muy fuerte, al partir de la idea de que este mundo, basado en la novedad permanente, no es sostenible porque lo único que produce es basura, ansiedad y ruido" (Muñoz Molina, entrevista personal, 04 de marzo de 2018b).

Por último, me parece relevante notar que la obra de Walter Benjamin, en tanto lector de su amigo Franz Hessel, aporta también una valiosa clave de interpretación a propósito de la proliferación de personajes biográficos en el libro de Muñoz Molina. En "El regreso del flâneur", la reseña que escribió a propósito de Paseos por Berlín de Hessel, Benjamin destaca atributos propios de una variante menos estudiada pero no menos importante del flâneur: Aquel que, "atravesando una ciudad, se muestra sensible a las huellas que los residentes o viajeros anteriores han dejado allí”. Según Muñoz-Millanes, traductor del escritor berlinés, para Benjamin

cada paso del flâneur despierta ecos del pasado, resuena en otro tiempo. Todas las calles de la ciudad son para él cuesta abajo por- 
que lo arrastran a múltiples pasados. 'El flâneur es el sacerdote del genius loci: igual que el perro de fino olfato o el detective eficiente, al toparse con las huellas en los lugares, el flâneur las rescata de su condición residual, ya que por su mediación es capaz de remontarse hasta los hechos en ellos acaecidos (2015: 13).

Muñoz-Millanes nos recuerda también que el arquitecto y urbanista italiano Aldo Rossi concibe la ciudad como un palimpsesto, es decir, "como una superposición de huellas depositadas a lo largo del tiempo donde los múltiples pasados urbanos sobreviven, precariamente y confundidos, de manera virtual" (Muñoz-Millanes, 2015: 13). Para Muñoz-Millanes, al caminar por Berlín la mirada de flâneur de Hessel va levantando, como si se tratara de un hojaldre, las diferentes capas de un pasado que insiste en aparecer en el presente, suspendido en la materialidad de una huella. Ayudado por sus propios recuerdos o por testimonios ajenos -como los de otros paseantes de la literatura, por ejemplo- el flâneur "despliega las fases de su evolución diacrónica”, lo cual le permite "asomarse a vidas y épocas ajenas, a experiencias olvidadas o que exceden su memoria. Y, al perderse en esos detalles minúsculos "termina despojándose de su individualidad” (Muñoz-Millanes, 2015: 13). A continuación, un ejemplo de cómo Muñoz Molina, paseante memorioso e imaginativo, recurre al juego de las vidas conjeturales y paralelas:

Tú Solo tienes que Cerrar los Ojos. En el tiempo pero no en el espacio se cruza con Benjamin Fernando Pessoa, caminante agitado por la ciudad a la que Walter Benjamin quiso llegar y no llegó, Lisboa, su puerto de tránsito en la huida hacia América. Otros amigos y conocidos suyos habían pasado por Lisboa y quizás le habían mandado cartas y postales desde allí. En vísperas del fin del mundo seguía funcionando con puntualidad el correo. 
Fernando Pessoa camina por la ciudad al mismo tiempo que Benjamin por París. Los dos son miopes, usan gafas redondas, visten con una extrema formalidad algo desgastada, sienten un gran interés por la grafología. Los dos llevan siempre una gran cartera negra. Wilde se había querido esconder bajo un nombre falso. Walter Benjamin había publicado artículos con pseudónimo en la prensa alemana cuando su nombre ya estaba proscrito. Pessoa se esconde o se multiplica en identidades inventadas. Dobles o sombras de Fernando Pessoa caminan por las calles de la Baixa, por la orilla del Tajo, por las cuestas del Chiado y del Bairro Alto. En las fotos, Fernando Pessoa y Walter Benjamin se parecen mucho, dobles posibles o heterónimos el uno del otro (Muñoz Molina, 2018a: 139).

\section{Reciclaje y recomposición del yo}

El tópico de la pérdida de individualidad sirve aquí al escritor para ser otro, lo cual queda subrayado por el cambio de pronombre en la instancia narradora, y por la invitación implícita a ver el recorrido del cronista como variante de una experiencia estética compartida por muchos. Reutilizando una técnica que ya había empleado en Ventanas de Manhattan o en muchos de sus artículos periodísticos, Muñoz Molina elabora en esta obra retratos de artistas plásticos contemporáneos que permiten al escritor revelar el código que sostiene su propio trabajo. Un ejemplo interesante en este sentido es Alexander Farto, Vhils, artista urbano que hace rostros de gran formato en edificios abandonados o en mal estado mediante la excavación parcial de los muros. Con ayuda de cincel y martillo, $\mathrm{y}$ a veces también erosionando con dinamita algunas zonas de la construcción de modo que alcancen a apreciarse todas sus capas superpuestas, Vhils busca llamar la atención sobre diferentes aspectos de la vida en la ciudad a partir de la idea de que "la des- 
trucción forma parte de la creación". Puede apreciarse el juego de correspondencias entre esta búsqueda artística y el libro de Muñoz Molina en el siguiente fragmento:

El talento Se inspira en las aceras. A Alexander Farto, Vhils, veintinueve años, le sigue asombrando la calle, donde se creó artísticamente: el caos de la gran ciudad, la depredación humana en la megalópolis, el ciclo incesante de producción y destrucción. No es un crítico del consumismo humano, ni un apóstol del reciclaje; es, más bien, un observador de esa actividad frenética de quita y pon del urbanita. Sus inmensos rostros con el acné de las paredes transmiten perplejidad más que sufrimiento y amargura. Son rostros plácidos, de aquí estoy y aquí sigo; usted, seguramente, no (Muñoz Molina, 2018a: 129).

Otro modelo estético de la ambiciosa crónica urbana de $\mathrm{Mu}$ ñoz Molina es el que ofrecen los muros de la Alhambra que, en su abigarramiento, recuerdan la profusión de la publicidad callejera en las ciudades contemporáneas, la piel tatuada de muchos individuos y páginas de esos cuadernos que él llena con palabras escritas con lápiz, en letra muy pequeña:

El FUtURo LATE CON MÁs FUERZa QUE NUNCA. Cada superficie ha de ser ocupada del todo, cada espacio libre, cada centímetro, como los muros de la Alhambra con letreros en árabe y mosaicos geométricos de azulejos, como un cuerpo tatuado de la cabeza a los pies. No hay lugar en que no pueda escribirse un mensaje: un cartón de leche, el carro del cartero, el respaldo de los asientos en un taxi, la pantalla del cajero automático, la farola de la calle y el reverso de una señal de tráfico, el lateral de un puente en la autopista hacia el aeropuerto [...]. El tiempo se ocupa tan exhaustivamente como el espacio. En los anuncios de la radio la gente habla 
muy alto y muy rápido. Los locutores hablan con una rapidez que se les contagia de los anuncios y que acelera el tránsito hacia el próximo bloque publicitario [...] (Muñoz Molina, 2018a: 132).

Tras leer esta obra desbordante, caótica y ecléctica, puede decirse que, acorde a la naturaleza del paseante urbano que evoca en sus páginas, Un andar solitario entre la gente es el viaje que el autor emprende al centro de sí mismo a partir de una invitación que, según cuenta en el siguiente fragmento, comenzó a tomar sentido para Muńoz Molina en Granada, en el inicio de su carrera y en la época en la que él emprendió la escritura de las crónicas urbanas de El Robinson urbano:

La invitación al viaje de Baudelaire estaba cumpliéndose gratuitamente para mí en la ciudad donde vivía, a dos pasos de la oficina donde trabajaba. Miraba y escuchaba la ciudad hasta que mi conciencia se disolvía en ella como si me sumergiera en un sueño de opio, y también me veía desde fuera. Veía la silueta del que camina solo entre la gente, un príncipe de incógnito, dice Baudelaire, un indigente, un intoxicado de láudano, un agente extranjero, un perseguidor del rastro de otros, un hombre bondadoso que camina por Dublín con una patata en el bolsillo del abrigo, un enamorado que dobla cada esquina con un estremecimiento de anticipación, un regresado desde muy lejos, desde otras vidas o regiones del tiempo, un náufrago en la ciudad como en una isla deshabitada, son las gafas de miope de Fernando Pessoa y de Walter Benjamin, con una cartera negra y muy gastada que no se le separa nunca (Muñoz Molina, 2018a: 494).

Es en este último párrafo de Un andar solitario donde adquiere sentido esta experiencia vital y estética cuando, en compañía de los demás paseantes, el escritor consigue avistarse como esa silueta 
ajena que camina sola entre la gente, no en la ciudad sino en el recuerdo, no en el presente sino en ese río de tinta que no ha dejado de escribir a lo largo de su vida, tal como afirma en otro libro que, si bien no habla de la ciudad sino de los paseos del autor a lo largo del Hudson, permite ver esta crónica urbana del siglo XXI como un canto de amor a la escritura y al paseo reflexivo:

Escríbeme un río. Escribe ríos de tinta. La escritura como un río que no ha dejado de fluir desde que tengo uso de razón, un río de tiza sobre pizarra, de mina de lápiz sobre hojas rayadas de cuaderno escolar, de cinta de máquina de escribir, de pluma estilográfica, de bolígrafo barato, de rotulador Pilot de punta muy fina: cómo será de largo y sinuoso el río de todas las palabras que uno ha ido escribiendo a lo largo de su vida (Muñoz Molina, 2015: 26).

Un andar solitario entre la gente es una obra que da cuenta del recorrido que ha llevado a Antonio Muñoz Molina desde sus primeras crónicas hasta un estilo que reúne el impulso narrativo de sus mejores novelas, la capacidad de describir el mundo visible que encontramos en sus artículos periodísticos, y la voluntad de reflexionar sobre el pasado y el devenir del mundo.

Como hemos visto, este camino parte de la tradición literaria del flâneur del siglo XIX al tiempo que recupera tanto elementos de su vida como de su propia obra literaria. En resumen, Un andar solitario entre la gente puede leerse como un paseo por la crónica urbana -género en el cual se inscribe la obra- que consigue delinear las transformaciones vividas por las urbes del siglo XXI.

Como ocurre con las grandes ciudades, esta crónica no se construye sobre un terreno vacío sino sobre un pasado habitado por huellas y residuos de otras obras, propias y ajenas. Y, al igual que sucede en los paseos urbanos, recorrer las páginas de este libro no 
es únicamente una experiencia espacial sino también diacrónica, como la Alhambra y como los murales callejeros de Vihls.

\section{Bibliografía}

Araya Alarcón, René, s/f, "Configuración del Flâneur en Poeta en Nueva York de F. García Lorca”, Alpha, pp. 25-42.

Gracia, Jordi y Domingo Ródenas de Moya, 2015, Pensar por ensayos en la España del siglo XX, Edicions UAB, Bellaterra.

López, Nicolás, 2013, "El principio del montaje en Walter Benjamin”, Revista Lindes. Estudios sociales del arte y la cultura, núm. 6, pp. 1-13.

Muñoz-Millanes, José, 2015, "Prólogo", en Franz Hessel, Paseos por Berlin, Manolo Laguillo (trad.), Errata naturae, Madrid, pp. 7-16.

Muñoz Molina, Antonio, 1993, El Robinson urbano, Seix Barral, Barcelona.

,2001, Sefarad. Una novela de novelas, Alfaguara, Madrid, , 2018a, Un andar solitario entre la gente, Seix Barral, Barcelona.

, 2015, El faro del fin del Hudson, Oficio, colección Lindo \& Espinosa, Valencia.

, 2018b, "Nuestro mundo solo produce basura, ansiedad y ruido", entrevista de Anna María Iglesia, El Confdencial. Disponible en: https:/www.elconfidencial.com/ cultura/2018-03-04/antonio-munoz-molina-entrevista-un-andar-solitario_1529642/ (Consultado: 28/IX/2019).

Ródenas de Moya, Domingo, 2018, "Donde todo es ruido”, El Periódico. Disponible en: https:/www.elperiodico.com/es/ 
ocio-y-cultura/20180227/critica-munoz-molina-andar-solitario-gente-6653114 (Consultado: 28/IX/2019).

Valls, Fernando, 2018, "Del que observa, oye, corta y pega, camina y escribe", InfoLibre. Información libre e independiente. Disponible en: https:/www.infolibre.es/noticias/los_diablos_ azules/2018/05/04/del_que_observa_oye_corta_pega_camina_escribe_82423_1821.html (Consultado: 28/IX/2019).

Yurkiévich, Saúl, 1986, "Estética de lo discontinuo y fragmentario”, Acta Poética, vol. 6, núms. 1-2, pp. 53-69. 